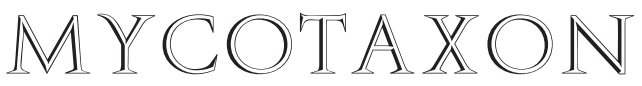

ISSN (print) 0093-4666 (online) 2154-8889 Mycotaxon, Ltd. ( $) 2017$

July-September 2017-Volume 132, pp. 471-483

https://doi.org/10.5248/132.471

\title{
Lactifluus persicinus sp. nov. from the gallery forests of West Cameroon
}

\author{
LyNN Delgat ${ }^{1 *}$, Eske De CROP ${ }^{1}$, \\ André-Ledoux NJOUONKOU ${ }^{2}$ \& ANNEMIEKe VERBEKEN ${ }^{1}$ \\ ${ }^{1}$ Department of Biology, Ghent University, \\ Karel Lodewijk Ledeganckstraat 35, Ghent, Belgium \\ ${ }^{2}$ Department of Biological Sciences, University of Bamenda, \\ 39 Bambili, Nord-Ouest, Cameroon \\ *Correspondence to: lynn.delgat@ugent.be
}

Aвstract-During field work in the Noun division of western Cameroon during 2011, 2012, and 2014, several collections of an unknown Lactifluus species were discovered in a gallery forest with Uapaca guineensis. Molecular and morphological research shows that these collections represent a new species, Lactifluus persicinus, which is described in this paper. Lactifluus persicinus belongs to $L f$. sect. Xerampelini in $L f$. subg. Pseudogymnocarpi. KeY wORDs-Russulaceae, ectomycorrhizal fungi, tropical Africa, edible mushroom, pseudocryptic species

\section{Introduction}

The Russulaceae are a family containing important ectomycorrhizal genera. In 2008, molecular research challenged existing generic concepts, resulting in the splitting of Russula Pers. and Lactarius Pers. into four segregate generaLactarius, Russula, Multifurca Buyck \& V. Hofst., and Lactifluus (Pers.) Roussel (Buyck et al. 2008). The species-rich milkcap genus Lactifluus (Lf.) comprises about 150 described species worldwide. Furthermore, at least 17 (possibly up to 44) species still await description (De Crop et al. 2017). Lactifluus has a mainly tropical distribution, with the highest known diversity in tropical Africa (Bâ et al. 2012, De Crop et al. 2012, Maba 2015, Maba et al. 2015a, Van de Putte et al. 2009, Verbeken \& Walleyn 2010) and tropical Asia (Le 2007, Stubbe et al. 
.. Delgat \& al.

TABLE 1. Lactifluus $(L f$.) specimens and GenBank sequences used in the molecular analyses. Type specimens are annotated as $[\mathrm{T}]$.

\begin{tabular}{|c|c|c|c|c|}
\hline Species & VOUCHER (HERBARIUM) & Country & ITS & LSU \\
\hline \multicolumn{5}{|c|}{ Lactifluus sect. Pseudogymnocarpi } \\
\hline Lf. cf. pseudogymnocarpus & AV 05-085 (GENT) & Malawi & KR364012 & KR364139 \\
\hline Lf. cf. pumilus & EDC 12-066 (GENT) & Cameroon & KR364067 & KR364196 \\
\hline \multirow[t]{2}{*}{ Lf. gymnocarpoides } & JD 885 (BR) & Congo & KR364074 & KR364203 \\
\hline & AV 05-184 (GENT) & $\begin{array}{l}\text { Malawi } \\
\text { North }\end{array}$ & KR364024 & KR364151 \\
\hline Lf. hygrophoroides & AV 05-251 (GENT) & America & HQ318285 & HQ318208 \\
\hline Lf. longisporus & AV 94-557 (GENT) [T] & Burundi & KR364118 & KR364244 \\
\hline Lf. luteopus & AV 94-463 (GENT) [T] & Burundi & KR364119 & - \\
\hline Lf. medusae & EDC 12-152 (GENT) & Cameroon & KR364069 & KR364198 \\
\hline Lf. pseudoluteopus & FH 12-026 (GENT) & Thailand & KR364084 & KR364214 \\
\hline Lf. sudanicus & AV 11-174 (GENT) [T] & Togo & HG426469 & KR364186 \\
\hline \multicolumn{5}{|l|}{ Lactifluus sect. Xerampelini } \\
\hline \multirow[t]{5}{*}{ Lf. persicinus } & EDC 14-371 (GENT) & Cameroon & KX499389 & - \\
\hline & EDC 12-002 (GENT) & Cameroon & KX499392 & KX622761 \\
\hline & EDC 12-004 (GENT) & Cameroon & KX499390 & KX622760 \\
\hline & EDC 12-001 (GENT) [T] & Cameroon & KR364061 & KR364190 \\
\hline & NAL 348 (GENT) & Cameroon & KX499391 & - \\
\hline Uncultured ectomycorrhiza & - & Guinea & AM113441 & - \\
\hline Lf. goossensiae & AB 320 (GENT) & Guinea & KR364132 & KR364252 \\
\hline \multirow[t]{2}{*}{ Lf. cf. pseudovolemus } & ADK 2927 (BR) & Benin & KR364113 & KR364243 \\
\hline & ADK 2968 (BR) & Benin & KX499393 & - \\
\hline \multirow[t]{3}{*}{ Lf. kivuensis } & JR Z366 (GENT) & Congo & KX499399 & - \\
\hline & JR Z439 (GENT) & Congo & KX499398 & - \\
\hline & JR Z 310 (GENT) [T] & Congo & KR364027 & KR364154 \\
\hline \multirow[t]{2}{*}{ Lf. rubiginosus } & JD 959 (BR) & Congo & KR364081 & KR364210 \\
\hline & BB 3466 (GENT) [T] & Zambia & KR364014 & KR364250 \\
\hline \multirow[t]{3}{*}{ Lf. xerampelinu } & TS 1116 (GENT) [T] & Tanzania & KR364039 & KR364166 \\
\hline & MH 201176 (GENT) & Mozambique & KR364099 & KR364231 \\
\hline & CS 2889 (GENT) & Zimbabwe & KX499394 & - \\
\hline \multirow[t]{3}{*}{$L f . \mathrm{sp}}$. & EDC 12-176 (GENT) & Cameroon & KR364070 & KR364199 \\
\hline & EDC 12-071 (GENT) & Cameroon & KX499396 & KX622762 \\
\hline & EDC $14-284$ & Cameroon & KX499395 & - \\
\hline Uncultured ectomycorrhiza & - & Gabon & FR731875 & - \\
\hline$L f . \mathrm{sp}$. & AV 11-022 (GENT) & Tanzania & KX499397 & KX622763 \\
\hline \multicolumn{5}{|l|}{ Unnamed clade } \\
\hline \multirow[t]{3}{*}{$L f . \mathrm{sp}}$. & JN 2011-012 (GENT) & Vietnam & KR364045 & KR364171 \\
\hline & TENN 065929 (TENN) & $\begin{array}{l}\text { North } \\
\text { America }\end{array}$ & KR364102 & KR364233 \\
\hline & EDC 14-501 (GENT, MFLU) & Thailand & KR364127 & - \\
\hline Lf. volemoides & TS 0705 (GENT) [T] & Tanzania & KR364038 & KR364165 \\
\hline \multicolumn{5}{|l|}{ Lactifluus sect. Aurantiifolii } \\
\hline Lf. aurantiifolius & AV 94-063 (GENT) [T] & Burundi & KR364017 & KR364144 \\
\hline
\end{tabular}




\begin{tabular}{|c|c|c|c|c|}
\hline \multicolumn{5}{|c|}{ Lactifluus sect. Rubroviolascentini } \\
\hline Lf. aff. rubroviolascens & EDC 12-051 (GENT) & Cameroon & KR364066 & KR364195 \\
\hline Lf. carmineus & AV 99-099 (GENT) [T] & Zimbabwe & KR364131 & KR364251 \\
\hline Lf. denigricans & EDC 11-218 (GENT) & Tanzania & KR364051 & KR364178 \\
\hline Lf. kigomaensis & AV 11-006 (GENT) & Tanzania & KR364052 & KR364179 \\
\hline$L f . \mathrm{sp}$. & EDC 11-159 (GENT) & Tanzania & KR364050 & KR364177 \\
\hline \multicolumn{5}{|c|}{ Lactifluus sect. Polysphaerophori } \\
\hline Lf. pegleri & PAM/Mart 12-091 (LIP) & Martinique & KP691416 & KP691425 \\
\hline \multirow[t]{3}{*}{$L f$. sp. } & RC/Guy 09-036 (LIP) & French Guiana & KJ786645 & KJ786550 \\
\hline & MR/Guy 13-145 & French Guiana & KJ786691 & KJ786595 \\
\hline & MCA 3937 (GENT) & Guyana & KR364109 & KR364240 \\
\hline Lf. veraecrucis & M 8025 (ENCB) [T] & Mexico & KR364112 & KR364241 \\
\hline \multicolumn{5}{|c|}{ Outgroup (Lf. subg. Lactifluus) } \\
\hline Lf. corrugis s.l. & AV 05-392 (GENT) & $\begin{array}{l}\text { North } \\
\text { America }\end{array}$ & JQ753822 & KR364143 \\
\hline Lf. crocatus & KVP 08-034 (GENT) & Thailand & HQ318243 & HQ318151 \\
\hline Lf. vitellinus & KVP 08-024 (GENT) & Thailand & HQ318236 & HQ318144 \\
\hline Lf. volemus & KVP 11-002 (GENT) & Belgium & JQ753948 & KR364175 \\
\hline Lf. acicularis & KVP 08-002 (GENT) & Thailand & HQ318226 & HQ318132 \\
\hline
\end{tabular}

2010, Van de Putte 2012, Van de Putte et al. 2010). Species diversity is high in the Guineo-Sudanian domain (Maba 2015; Maba et al. 2014, 2015a, 2015b), with around 38 Lactifluus species currently known from the area. However, certain regions within this area remain poorly explored with potentially many new species yet to be discovered and described. In one such region, Cameroon, most studies have been located in the tropical rainforest (Douanla-Meli \& Langer 2009, Verbeken et al. 2008), and little is known about milkcaps in the savannas, from which only one Lactifluus species, $L f$. albomembranaceus S. De Wilde \& Van de Putte, has been described (De Crop et al. 2016).

Southern Cameroon is dominated by closed evergreen lowland forest, while the centre of the country is dominated by deciduous woodland and shrubland (WRI 2003). The tropical forest does not undergo a gradual change to savanna or woodland; instead the zone between these two habitats consists of habitat patches with abrupt borders. This transition zone is called the 'forest-savanna mosaic' since it contains forest islands and savannas, as well as woodlands (White 1983). In contrast to savannas and woodlands, dense tree cover characterizes the forest islands, with the resulting competition for light leading to an understory with much lower abundances of grasses than in the savannas or woodlands (Azihou et al. 2013, Hoffmann et al. 2009, Natta et al. 2003). Forest islands that occur alongside waterways are known as gallery forests. The plant groups Caesalpinioideae (represented by Berlinia Sol. ex Hook. f.) 
and Phyllanthaceae (represented by Uapaca Baill.) dominate the Central and West African gallery forests. These trees are ectomycorrhizal hosts, making the humid gallery forests an ideal habitat in which to find ectomycorrhizal fungi.

A recent survey of wild mushrooms in the West region of Cameroon revealed nine edible Lactifluus species, all collected in gallery forests (Njouonkou et al. 2016). From the same division, Lf. albomembranaceus was described (De Crop et al. 2016). It is from this habitat that the new species described here, Lactifluus persicinus, was discovered.

\section{Materials \& methods}

\section{Sampling}

During fieldwork in 2011, 2012, and 2014 in gallery forests within the Noun division of western Cameroon, 15 collections of Lactifluus persicinus were made.

\section{Morphological analysis}

Macroscopic characters were observed from fresh material, with colour codes referring to Kornerup \& Wanscher (1978). Microscopic characters were observed from dried material. Spores were mounted in Melzer's reagent and measured in side view without ornamentation. A total of 186 spores were measured among 14 collections. The measurements are given as $[A v a-2 x S D a]-A v a-A v b-[A v b+2 x S D b]$ in which $A v a=$ lowest mean value for the measured collections, $A v b=$ greatest mean value and $\mathrm{SDa} / \mathrm{b}=$ standard deviation of the lowest and greatest mean value respectively. As an indication for spore shape, Q was also determined, where $\mathrm{Q}$ is the quotient of length and width and is given as MINQ- $A v Q a-A v Q b-\mathrm{MAXQ}$, with $A v Q a$ and $A v Q b$ the lowest and the highest mean quotient, respectively, for the measured specimens. MINQ/MAXQ stands for the minimum/maximum value over the quotients of all available measured spores. The hymenium, pileipellis and stipitipellis were mounted in Congo red. The measurements of the basidia do not include the sterigmata. Line drawings were made with the aid of a drawing tube at following magnifications: $6000 \times$ for spores (Zeiss Axio Scope 2 microscope), $1500 \times$ for other hymenial elements and sections (Olympus cx31 microscope). For the SEM pictures, the spores were coated in a Quorum Q150TS sputter coater with $5 \mathrm{~nm}$ thick Pt/Pd (platinum palladium) and studied using a Jeol JSM-7600F Field Emission Scanning Microscope.

\section{Molecular analysis}

DNA from dry collections was extracted using the protocol described by Nuytinck \& Verbeken (2003) with modifications described in Van de Putte et al. (2010). DNA was extracted from fresh material using the CTAB extraction described in Nuytinck \& Verbeken (2003). Protocols for PCR amplification follow Le et al. (2007). Two nuclear markers previously shown as informative within this subgenus (De Crop et al. 2017) were used: (1) the internal transcribed spacer region of ribosomal DNA (ITS), comprising the ITS1 and ITS2 spacer regions and the ribosomal gene 5.8S, using primers ITS- $1 \mathrm{~F}$ and 
ITS4 (Gardes \& Bruns 1993, White et al. 1990) and (2) a part of the ribosomal large subunit 28 S region (LSU), using primers LR0R and LR5 (Moncalvo et al. 2000).

PCR products were sequenced using an automated ABI 3730 XL capillary sequencer (Life Technology) at Macrogen. Forward and reverse sequences were assembled into contigs and edited where needed with the Sequencher v5.0 software (Gene Codes Corporation, Ann Arbor, MI, U.S.A.).

From De Crop et al. (2017) we knew that Lactifluus persicinus represented Lactifluus subg. Pseudogymnocarpi (Verbeken) De Crop and Lf. sect. Xerampelini De Crop. The dataset for phylogenetic analyses contained sequences from Lactifluus subg. Pseudogymnocarpi (De Crop et al. 2017) and we added more newly generated sequences plus two GenBank sequences within $L f$. sect. Xerampelini. For other sections only one sequence per species was included. Five species representing $L f$. subg. Lactifluus were used as outgroup (TABLE 1).

Sequences were aligned online using the E-INS-I strategy version of the multiple sequence alignment program MAFFT v7 (Katoh \& Toh 2008). Trailing ends were trimmed and the alignment was manually edited when necessary in Mega 6 (Tamura et al. 2013). The alignment can be obtained from the first author and TreeBASE (Submission ID 19693). The alignment was partitioned into partial 18S, ITS1, 5.8S, ITS2 and partial 28S. Maximum likelihood (ML) analyses were conducted with RAxML v8.0.24 (Stamatakis 2014), where a ML analysis was combined with the Rapid Bootstrapping algorithm with 1000 replicates under the GTRCAT option (Stamatakis et al. 2008). All analyses were performed on the CIPRES Science Gateway (Miller et al. 2010).

\section{Results}

The molecular results placed the new species in $L f$. subg. Pseudogymnocarpi and $L f$. sect. Xerampelini. Its sister clade contains collections previously identified as $L f$. goossensiae (Beeli) Verbeken from Guinea and $L f$. cf. pseudovolemus (R. Heim) Verbeken from Benin. The new species, described below as $L f$. persicinus, is morphologically very similar to the collections within this sister clade with which it is compared.

Lactifluus persicinus Delgat \& De Crop, sp. nov.

FIGS 1-3

\section{MycoBank MB 817873}

Differs morphologically from its sister clade (collections AB 320, ADK 2927 and ADK 2968) by its shorter basidia.

TYPE: Cameroon, Western region, Noun division, Koutaba subdivision, Mamevouo village, gallery forest in savannah region, Uapaca guineensis, $5^{\circ} 41^{\prime} 01^{\prime \prime} \mathrm{N} 10^{\circ} 49^{\prime} 28^{\prime \prime} \mathrm{E}$, 1126 m, 8 May 2012, EDC 12-001 (Holotype, GENT)

ЕтумоLоgy: Referring to the peach-like color and surface of the basidiocarp.

Pileus 37-73 mm diam., firm, plano-concave with depressed centre to deeply infundibuliform; margin straight to inflexed, broadly grooved (c. 2-3 mm) 


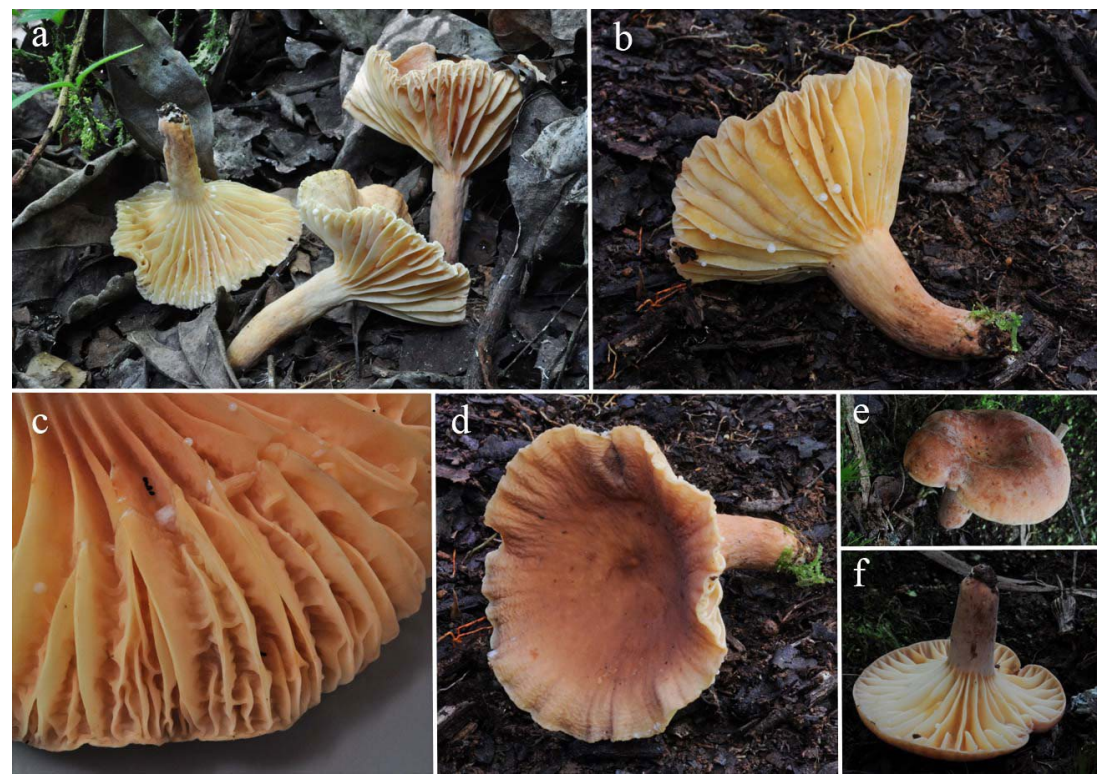

FIG. 1. Lactifluus persicinus basidiocarps: a. holotype, EDC 12-001; b. EDC 14-349; c. EDC 12-002; d. EDC 14-349; e. EDC 14-380; f. EDC 14-380. (Photos by E. De Crop).

reaching halfway across the pileus; surface chamois-leather-like, slightly velutinous when young, cream yellow to orange to pink (5A3-6A2), some pilei slightly darker (6B4-7C4), locally more pink or more yellow, concentrically wrinkled near margin. STIPE 32-48×8-14 mm, cylindrical, sometimes tapering downwards or curving at the base; surface slightly irregular, almost smooth, very soft (softer than pileus), slightly velutinous or chamois-leather-like, almost concolourous with pileus but slightly paler, cream yellow-orange (5A3,5A4 to $6 \mathrm{~A} 3$ ), sometimes with a pinkish tinge, pale at top, becoming darker orange towards the base (5A5-5B5). LAMELLAE decurrent with rather long teeth, very broad, thick, strongly transvenose and slightly intervenose, sometimes bifurcating towards the margin, brittle, distant $(2+3-5 \mathrm{~L}+1 \mathrm{l} / \mathrm{cm})$, paler than pileus, cream yellow with pinkish tinge (4A3-5A2); edge concolourous and entire. ConTEXT white, firm, unchanging, unchanging with guaiac, slightly pink with $\mathrm{FeSO}_{4}$. SMell not remarkable. Taste mild. Latex abundant, watery white, unchanging, taste mild.

BASIDIOSPOREs broadly ellipsoid to ellipsoid, rarely slightly elongate, 6.99.2-10.9-12.8 ×5.7-6.7-7.7-9.4 $\mathrm{m}(\mathrm{Q}=1.10-1.33-1.48-1.70)$; ornamentation amyloid, composed of low (1 $\mu \mathrm{m}$ at most) elongated warts, aligned or connected 
a

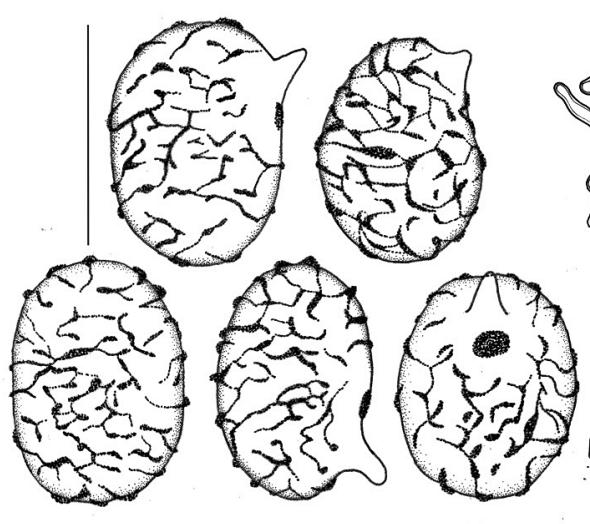

c

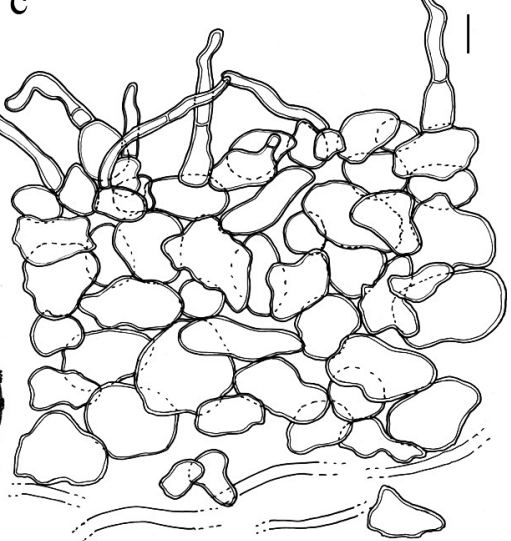

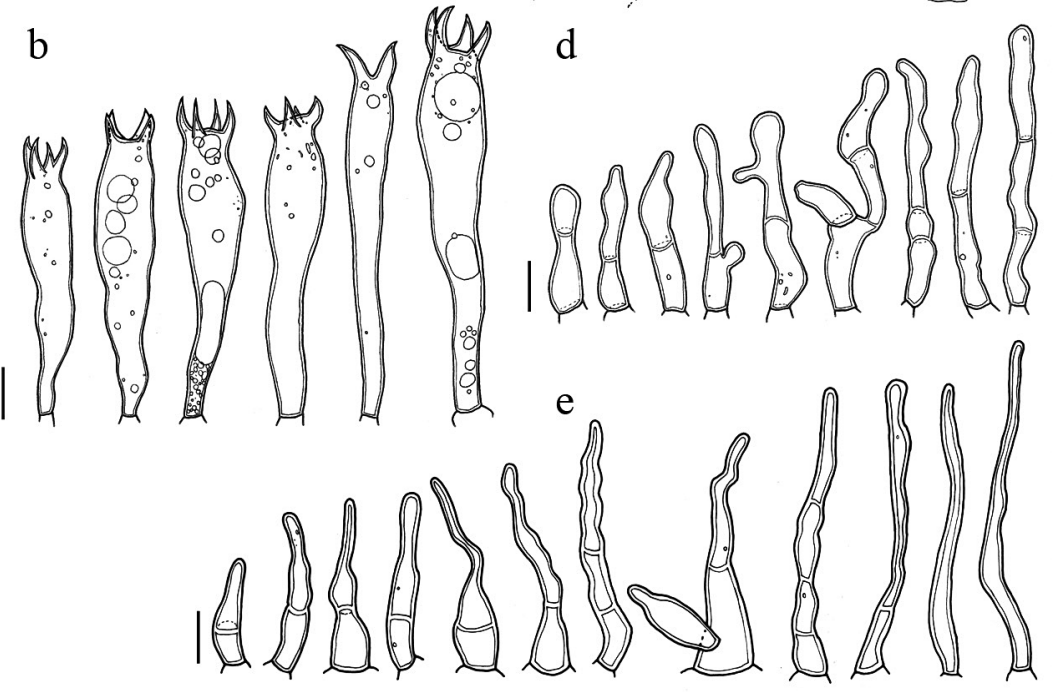

FIG. 2. Lactifluus persicinus: a. basidiospores; b. basidia; c. section through the pileipellis; d. sterile elements from the hymenium; e. pileipellis hairs. Scale bar $=10 \mu \mathrm{m}$. (Line drawings by L. Delgat).

by fine connective lines, forming an incomplete reticulum, with only few isolated warts; plage sometimes distinct and with a central amyloid spot. BAsidia $45-74(-90) \times(8-) 8.5-11.5(-12.5)$, cylindrical to subclavate, 4 -spored, rarely 2-spored, slightly thick-walled. Sterile elements abundant, 21-60 × 3.5-7 $\mu \mathrm{m}$, some emergent, majority not emergent, cylindrical, septate, with rounded apex, wall slightly thickened. Pleurocystidia absent. Pleuropseudocystidia 

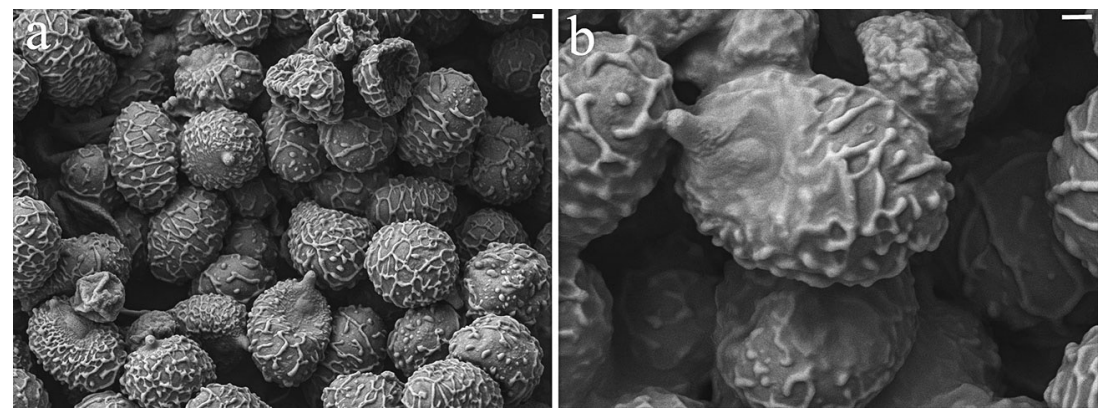

FIG. 3. Lactifluus persicinus (holotype, EDC 12-001) basidiospores (SEM): a. overview; b. detail of basidiospores. Scale bars $=1 \mu \mathrm{m}$.

scarce, 6-10 $\mu \mathrm{m}$ diam., cylindrical with rounded apex, often remarkably emergent, sometimes not emergent. LAMELLAR EDGE fertile. HyMENOPHORAL TRAMA cellular, with lactifers and sphaerocytes. Pileipellis a lampropalisade; elements of the suprapellis $19-65 \times 3-11 \mu \mathrm{m}$, cylindrical to cylindrical with broadened base, often septate, thick-walled; subpellis composed of slightly thick-walled globose/isodiametric cells (10-30 $\mu \mathrm{m}$ diam.), up to $80 \mu \mathrm{m}$ thick. STIPITIPELLIS a lamprotrichoderm to lamprotrichopalisade, with many parallel hyphae, part of them ascending; terminal elements more abundant than in the pileipellis, occurring in tufts, cylindrical, cylindrical with a bulbous base or broadly ellipsoid to globose, often septate, slightly thick-walled.

Use - Lactifluus persicinus is used as food by Bamoun people in the Noun division of the west region of Cameroon.

LOCAL NAME - Lactifluus persicinus is locally called "Puo' mbum mon (pwó' mbtm mon)" by Bamoun people. "Puo" is a general word for mushroom. "Mbum mon" is the local name of a herbaceous Euphorbia species, namely Euphorbia heterophylla L., which is an annual plant with white milky latex in all parts of the plant. This name is related to the fact that Lactifluus persicinus produces abundant white latex like Euphorbia species. However, this name also seems to be used for other milkcap species.

Ecology - found in Cameroon in the 'forest-savanna mosaic' zone in gallery forests with Uapaca guineensis Müll. Arg.

Distribution - known only from Cameroon.

AdDitionAl SPECIMENS EXAMINED - CAMEROON, WESTERN REgION, Noun division, Koutaba subdivision, Mamevouo village, gallery forest in savannah region, Uapaca guineensis, $5^{\circ} 41^{\prime} 01^{\prime \prime} \mathrm{N} 10^{\circ} 49^{\prime} 28^{\prime \prime} \mathrm{E}, 1126 \mathrm{~m}, 8$ May 2012, EDC 12-002, EDC 12003, EDC 12-004 (GENT); 539'12"N 1050'54"E, 1062 m, 10 May 2012, EDC 12-050 (GENT); $5^{\circ} 40^{\prime} 59^{\prime \prime} \mathrm{N} 10^{\circ} 49^{\prime} 29^{\prime \prime} \mathrm{E}, 1122 \mathrm{~m}, 27$ May 2014, EDC $14-349$ (GENT); $5^{\circ} 40^{\prime} 48^{\prime \prime} \mathrm{N}$ 
$10^{\circ} 49^{\prime} 28^{\prime \prime}$ E, 1139 m, EDC 14-361 (GENT); 539'27"N 10 50'57"E, 1063 m, 29 May 2014, EDC 14-371 (GENT); 539'26"N 1050'57"E, 1113 m, EDC 14-374 (GENT); $5^{\circ} 39^{\prime} 10^{\prime \prime} \mathrm{N} 10^{\circ} 51^{\prime} 00^{\prime \prime} \mathrm{E}, 1117 \mathrm{~m}$, EDC 14-376 (GENT); 5 $39^{\prime} 10^{\prime \prime} \mathrm{N} 10^{\circ} 51^{\prime} 01^{\prime \prime} \mathrm{E}, 1093 \mathrm{~m}$, EDC 14-378 (GENT); 5 $38^{\prime} 60^{\prime \prime} \mathrm{N} 10^{\circ} 51^{\prime} 05^{\prime \prime} \mathrm{E}, 1117 \mathrm{~m}$, EDC 14-380 (GENT); 5 $38^{\prime} 58^{\prime \prime} \mathrm{N}$ $10^{\circ} 51^{\prime} 03^{\prime \prime} \mathrm{E}, 1120 \mathrm{~m}$, EDC 14-385, EDC 14-386 (GENT); 5³9'37"N 1050'48" $\mathrm{E}, 1099$ m, 22 August 2011, NAL 348 (GENT).

\section{Discussion}

Lactifluus persicinus is recognizable in the field as a typical Lactifluus because of the chamois-leather-like surface of the cap. This is confirmed under the microscope by the cellular hymenophoral trama and the lampropalisade pileipellis structure. Molecular data also confirm placement within Lactifluus (FIG. 4).

Within the genus, Lactifluuspersicinus belongs to $L f$. subg. Pseudogymnocarpi, which is supported by molecular data (De Crop et al. 2017), as well as by morphological characters, such as the lampropalisade pileipellis structure, yellow/orange cap colour, and absence of colour reactions of the latex as in most species of this subgenus.

Lactifluuspersicinus is placed within the section $L f$. sect. Xerampelini, a section containing exclusively African species (FIG. 4). It also fits morphologically within this clade, which is characterized by yellowish-orange to reddish-brown cap colours, palisade-like pileipellis structure, absence of clear cystidia, and generally low ornamented spores (usually not higher than $0.2 \mu \mathrm{m}$ ) that are verrucose or form a more or less complete reticulum.

The sister clade of $L f$. persicinus contains collections previously identified as $L f$. goossensiae and $L f$. cf. pseudovolemus (FIG. 4) from Guinea and Benin. However, Lf. pseudovolemus is known only from Madagascar, and several macro- and microscopic characters mentioned in the description (Heim 1938) are not concordant with characters of the collections in this clade. In addition, we have studied the type material of $L f$. goossensiae and this species also seems to differ both macro- and microscopically from the sequenced collections in this clade (e.g. the type of $L f$. goossensiae has smaller spores). It seems likely that this sister clade represents neither $L f$. pseudovolemus nor $L f$. goossensiae. As it was not possible to obtain sequences from the types of $L f$. pseudovolemus and $L f$. goossensiae to test the two species molecularly, the identities of the specimens assigned to the sister clade remain unconfirmed.

Although Lactifluus persicinus is clearly delimited from its sister clade molecularly, morphologically the two clades are difficult to distinguish from each other and might be considered (pseudo) cryptic species. Macroscopically 


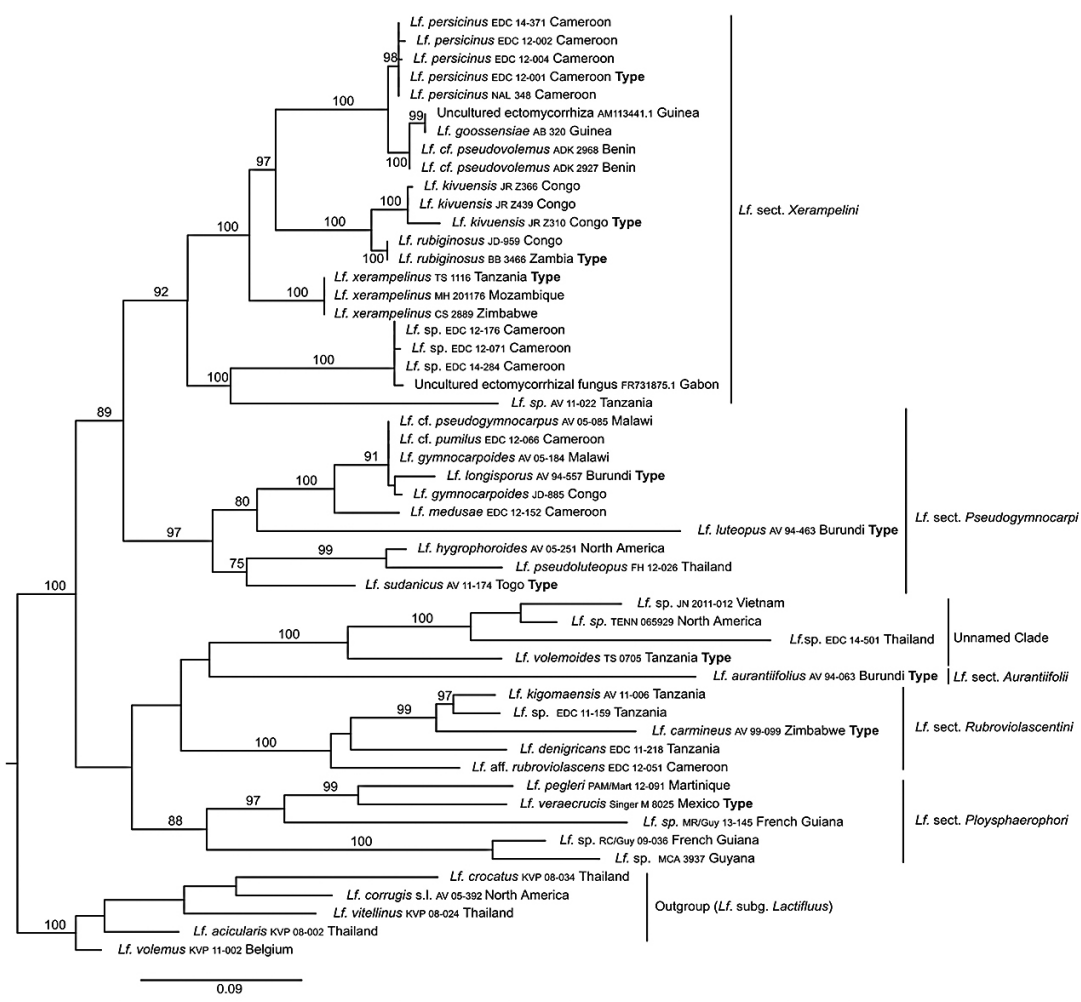

Fig. 4. Overview Maximum Likelihood tree of Lactifluus subg. Pseudogymnocarpi, based on concatenated ITS and LSU sequence data. ML bootstrap values $>70 \%$ are shown.

the species look alike; colours and lamellae are similar, as well as the fruit body shape, cap surface, and the latex. Microscopically they are also similar. The spore sizes correspond-7.9-9.3-10.7-13.8 × 5.9-6.8-7.9-9.0 $\mu \mathrm{m}$ (sister clade) vs. 6.9-9.2-10.9-12.8 $\times$ 5.7-6.7-7.7-9.4 $\mu \mathrm{m}$ ( $L f$. persicinus $)$-as do the spore shapes $-\mathrm{Q}=1.18-1.35-1.39-1.66$ (sister clade) vs. $\mathrm{Q}=1.10-1.33-$ 1.48-1.70 (Lf. persicinus). Basidia sizes overlap-55-90 × 9.5-11.5 $\mu \mathrm{m}$ (sister clade) vs. $45-74(-90) \times(8-) 8.5-11.5(-12.5) \mu \mathrm{m}$ (Lf. persicinus). However, the average basidial length differs substantially $-74 \times 10 \mu \mathrm{m}$ (sister clade) vs. 56 $\times 10 \mu \mathrm{m}$ ( $L f$. persicinus). So the sister clade has on average much longer and more slender basidia than Lactifluus persicinus. Collections of the sister clade also have similar sterile elements, which are often septate and slightly thickwalled, and the terminal elements of the pilei- and stipitipellis also look alike. In addition, they were collected in the same kind of habitat, namely in gallery 
forests. However, all currently known collections from Lactifluus persicinus were found in gallery forests dominated by Uapaca guineensis, while the three sister clade collections were found in gallery forests dominated by Uapaca somon $[=U$. togoensis Pax $]$.

In summary, while morphologically very similar, these species are genetically distinct and can be morphologically distinguished from each other when the average basidium length is compared. These species could be considered pseudocryptic species; at first they seemed indistinguishable, but after the phylogeny revealed two distinct species, detailed morphological study revealed (a) character(s) that can be used to morphologically distinguish them from each other. This phenomenon is widespread throughout Lactifluus and considered typical for this genus with its high molecular diversity and relatively low morphological diversity. Many species complexes occur in $L f$. subg. Lactifluus, $L f$. subg. Gymnocarpi, Lf. sect. Pseudogymnocarpi, etc. (De Crop 2016, Stubbe 2012, Van de Putte 2012) and as with most of these, the genetic distance between Lactifluus persicinus and its sister clade is rather low, as can be seen from the short-although well-supported-branches between them (FIG. 4). This may suggest a relatively recent divergence between species as well as insufficient time for significant morphological divergence to develop.

\section{Acknowledgments}

The first author was funded by a doctoral scholarship of the Special Research Fund (BOF). The 2014 survey in Cameroon was financially supported by the Research Foundation Flanders (FWO, grant V416214N) and the Leopold III fund. We would like to express our gratitude to all who helped during field work. The authors would also like to thank André De Kesel, for providing the $L f$. cf. pseudovolemus collections with his macroscopic notes and pictures. Thanks Bertie-Joan Van Heuven and Yoran Toonen for making the SEM pictures. We would also like to thank Ursula Eberhardt and Andy Taylor for reviewing this paper.

\section{Literature cited}

Azihou AF, Kakai RG, Bellefontaine R, Sinsin B. 2013. Distribution of tree species along a gallery forest-savanna gradient: patterns, overlaps and ecological thresholds. Journal of Tropical Ecology 29: 25-37. https://doi.org/10.1017/S0266467412000727

Bâ AM, Duponnois R, Moyersoen B, Diedhiou AG. 2012. Ectomycorrhizal symbiosis of tropical African trees. Mycorrhiza 22(1): 1-29. https://doi.org/10.1007/s00572-011-0415-X

Buyck B, Hofstetter V, Eberhardt U, Verbeken A, Kauff F. 2008. Walking the thin line between Russula and Lactarius: the dilemma of Russula subsect. Ochricompactae. Fungal Diversity 28: 15-40.

De Crop E. 2016. Global phylogeny and evolutionary history of the genus Lactifluus. Biology, Ghent University, Ghent. 
De Crop E, Tibuhwa D, Baribwegure D, Verbeken A. 2012. Lactifluus kigomaensis sp. nov. from Kigoma province, Tanzania. Cryptogamie, Mycologie 33(4): 421-426. https://doi.org/10.7872/crym.v33.iss4.2012.421

De Crop E, Van de Putte K, De Wilde S, Njouonkou AL, De Kesel A, Verbeken A. 2016. Lactifluus foetens and Lf. albomembranaceus sp. nov. (Russulaceae): look-alike milkcaps from gallery forests in tropical Africa. Phytotaxa 277(2): 159-170. https://doi.org/10.11646/phytotaxa.277.2.3

De Crop E, Nuytinck J, Van de Putte K, Wisitrassameewong K, Hackel J, Stubbe D, Hyde KD, Roy M, Halling RE, Moreau PA, Eberhardt U, Verbeken A. 2017. A multi-gene phylogeny of Lactifluus (Basidiomycota, Russulales) translated into a new infrageneric classification of the genus. Persoonia 38: 58-80.

Douanla-Meli C, Langer E. 2009. Fungi of Cameroon II. Two new Russulales species (Basidiomycota). Nova Hedwigia 88(3-4): 491-502. https://doi.org/10.1127/0029-5035/2009/0088-0491

Gardes M, Bruns TD. 1993. ITS primers with enhanced specificity for Basidiomycetes application to the identification of mycorrhizae and rusts. Molecular Ecology 2(2): 113-118. https://doi.org/10.1111/j.1365-294X.1993.tb00005.x

Heim R. 1938 ["1937"]. Les Lactario-Russulés du domaine oriental de Madagascar. Prodrome à une Flore Mycologique de Madagascar 1. 196 p.

Hoffmann WA, Adasme R, Haridasan M, de Carvalho MT, Geiger EL, Pereira MAB, Gotsch SG, Franco AC. 2009. Tree topkill, not mortality, governs the dynamics of savannaforest boundaries under frequent fire in central Brazil. Ecology 90(5): 1326-1337. https://doi.org/10.1890/08-0741.1

Katoh K, Toh H. 2008. Recent developments in the MAFFT multiple sequence alignment program. Briefings in Bioinformatics 9(4): 286-298. https://doi.org/10.1093/bib/bbn013

Kornerup A, Wanscher JH. 1978. Methuen handbook of colour, 3rd edition. Methuen, London.

Le HT. 2007. Biodiversity of the genus Lactarius (Basidiomycota) in northern Thailand. $\mathrm{PhD}$ dissertation, Chiang Mai University.

Le HT, Nuytinck J, Verbeken A, Lumyong S, Desjardin DE. 2007. Lactarius in Northern Thailand: 1. Lactarius subgenus Piperites. Fungal Diversity 24: 173-224.

Maba DL. 2015. Diversity, molecular phylogeny, ecology and distribution of the genera Lactifluus and Lactarius (Russulales, Basidiomycota) in West Africa. Ludwig-Maximilians Universität München, München.

Maba DL, Guelly AK, Yorou NS, Verbeken A, Agerer R. 2014. Two new Lactifluus species (Basidiomycota, Russulales) from Fazao Malfakassa National Park (Togo, West Africa). Mycological Progress 13(3): 513-524. https://doi.org/10.1007/s11557-013-0932-4

Maba DL, Guelly AK, Yorou NS, Agerer R. 2015a. Diversity of Lactifluus (Basidiomycota, Russulales) in West Africa: 5 new species described and some considerations regarding their distribution and ecology. Mycosphere 6(6): 737-759.

Maba DL, Guelly AK, Yorou NS, Verbeken A, Agerer R. 2015b. Phylogenetic and microscopic studies in the genus Lactifluus (Basidiomycota, Russulales) in West Africa, including the description of four new species. IMA Fungus 6(1): 13-24. https://doi.org/10.5598/imafungus.2015.06.01.02

Miller MA, Pfeiffer W, Schwartz T. 2010. Creating the CIPRES Science Gateway for inference of large phylogenetic trees. 1-8, in: Proceedings of the Gateway Computing Environments Workshop (GCE), 14 Nov. 2010, New Orleans. https://doi.org/10.1109/GCE.2010.5676129

Moncalvo JM, Lutzoni FM, Rehner SA, Johnson J, Vilgalys R. 2000. Phylogenetic relationships of agaric fungi based on nuclear large subunit ribosomal DNA sequences. Systematic Biology 49(2): 278-305. https://doi.org/10.1093/sysbio/49.2.278

Natta AK, Sinsin B, van der Maesen LJG. 2003. Riparian forests and biodiversity conservation in Benin (West Africa). 126-127, in: Proceedings of the 12th World Forestry Congress 2003. 
Njouonkou AL, De Crop E, Mbenmoun AM, Kinge TR, Biyé EH, Verbeken A. 2016. Diversity of edible and medicinal mushrooms used in the Noun division of the West Region of Cameroon. Journal of Medicinal Mushrooms, 18 (5): 387-396.

Nuytinck J, Verbeken A. 2003. Lactarius sanguifluus versus Lactarius vinosus-molecular and morphological analyses. Mycological Progress 2(3): 227-234. https://doi.org/10.1007/s11557-006-0060-5

Stamatakis A. 2014. RAxML version 8: a tool for phylogenetic analysis and post-analysis of large phylogenies. Bioinformatics 30(9): 1312-1313. https://doi.org/10.1093/bioinformatics/btu033

Stamatakis A, Hoover P, Rougemont J. 2008. A rapid bootstrap algorithm for the RAxML web servers. Systematic Biology 57(5): 758-771. https://doi.org/10.1080/10635150802429642

Stubbe D. 2012. Systematics and phylogeny of Lactarius subgenus Plinthogalus sensu lato. Faculty of Sciences, Ghent University, Ghent.

Stubbe D, Nuytinck J, Verbeken A. 2010. Critical assessment of the Lactarius gerardii species complex (Russulales). Fungal Biology 114(2-3): 271-283. https://doi.org/10.1016/j.funbio.2010.01.008

Tamura K, Stecher G, Peterson D, Filipski A, Kumar S. 2013. MEGA6: Molecular Evolutionary Genetics Analysis version 6.0. Molecular Biology and Evolution 30(12): 2725-2729. https://doi.org/10.1093/molbev/mst197

Van de Putte K. 2012. Hidden diversity exposed: A case study of Lactifluus volemus sensu lato. Biology, Ghent University, Ghent.

Van de Putte K, De Kesel A, Nuytinck J, Verbeken A. 2009. A new Lactarius species from Togo with an isolated phylogenetic position. Cryptogamie, Mycologie 30(1): 39-44.

Van de Putte K, Nuytinck J, Stubbe D, Huyen TL, Verbeken A. 2010. Lactarius volemus sensu lato (Russulales) from northern Thailand: morphological and phylogenetic species concepts explored. Fungal Diversity 45(1): 99-130. https://doi.org/10.1007/s13225-010-0070-0

Verbeken A, Walleyn R. 2010. Monograph of Lactarius in tropical Africa. Belgium, National Botanic Garden.

Verbeken A, Stubbe D, Nuytinck J. 2008. Two new Lactarius species from Cameroon. Cryptogamie, Mycologie 29(2): 137-143.

White JC. 1983. The vegetation of Africa. A descriptive memoir to accompany the Unesco/ AETFAT/UNSO vegetation map of Africa. Paris, UNESCO.

White TJ, Bruns T, Lee S, Taylor JW. 1990. Amplification and direct sequencing of fungal ribosomal RNA genes for phylogenetics. 315-322, in: MA Innis et al. (eds). PCR protocols: a guide to methods and applications. New York, Academic Press. https://doi.org/10.1016/B978-0-12-372180-8.50042-1

World Resources Institute (WRI). 2003. Cameroon: vegetation cover. http://www.wri.org/resources/maps/cameroon-vegetation-cover 